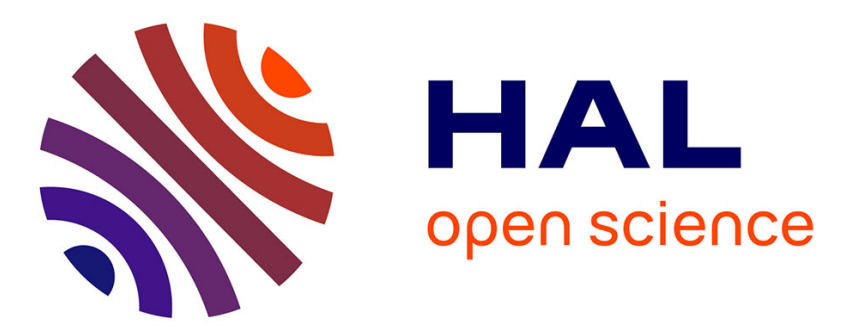

\title{
First-Principles Investigation of the Coupling-Induced Dissociation of Methane and its Transformation to Ethane and Ethylene
}

Jithin John Varghese, Bharathi Saravanan, Holger Vach, Gilles H. Peslherbe, Samir H Mushrif

\section{To cite this version:}

Jithin John Varghese, Bharathi Saravanan, Holger Vach, Gilles H. Peslherbe, Samir H Mushrif. FirstPrinciples Investigation of the Coupling-Induced Dissociation of Methane and its Transformation to Ethane and Ethylene. Chemical Physics Letters, 2018. hal-02401222

\section{HAL Id: hal-02401222 \\ https://hal.science/hal-02401222}

Submitted on 9 Dec 2019

HAL is a multi-disciplinary open access archive for the deposit and dissemination of scientific research documents, whether they are published or not. The documents may come from teaching and research institutions in France or abroad, or from public or private research centers.
L'archive ouverte pluridisciplinaire HAL, est destinée au dépôt et à la diffusion de documents scientifiques de niveau recherche, publiés ou non, émanant des établissements d'enseignement et de recherche français ou étrangers, des laboratoires publics ou privés. 


\section{First-Principles Investigation of the Coupling-Induced}

\section{Dissociation of Methane and its Transformation to Ethane}

\section{and Ethylene}

Jithin John Varghese, ${ }^{1,2}$ Bharathi Saravanan, ${ }^{1}$ Holger Vach, ${ }^{3}$ Gilles H.

Peslherbe, ${ }^{4}$ and Samir H. Mushrif ${ }^{1,5 *}$

${ }^{1}$ School of Chemical and Biomedical Engineering, Nanyang Technological University, 62

Nanyang Drive, Singapore 637459

${ }^{2}$ Cambridge Centre for Advanced Research and Education in Singapore (CARES) Ltd.,

Campus for Research Excellence and Technological Enterprise (CREATE), CREATE Tower,

1 CREATE Way, Singapore 138602

${ }^{3}$ Laboratoire de Physique des Interfaces et des Couches Minces, CNRS UMR-7647, Ecole Polytechnique, 91128 Palaiseau, France

${ }^{4}$ Centre for Research in Molecular Modelling and Department of Chemistry \& Biochemistry, Concordia University, Montréal, Québec, H4B 1R6, Canada

${ }^{5}$ Department of Chemical and Materials Engineering, University of Alberta, 9211 - 116 St.

NW, Edmonton, Alberta, T6G 1H9, Canada

•Email: mushrif@ualberta.ca (SHM) Ph: +1 780-492-4872 Fax: +1 780-492-2881 


\begin{abstract}
Quantum chemical computations predict that compression of the methane dimer to an internuclear separation lower than $2 \AA$ facilitates a concerted coupling and dissociation of C-H bonds of the molecules to form ethane/ethylene. In this bimolecular, concerted mechanism, ethane formation is accompanied by production of $\mathrm{H}$ radicals from each methane moiety that may further abstract hydrogen atoms to lead to ethylene formation. Alternatively, transformation to ethane and ethylene proceeds via stepwise molecular hydrogen elimination, with the first eliminated hydrogen molecule originating from one of the methane moieties, accompanied by an intermolecular hydrogen transfer, and the second originating from both methyl groups.
\end{abstract}

\title{
1. INTRODUCTION
}

Methane is the most abundant hydrocarbon in the universe and is part of many planetary systems, [1] making it a molecule of particular interest for astrophysicsts, astrochemists, and spectroscopists. [2] On earth, it exists in plentiful amounts in the form of resources like natural gas [3] and natural gas hydrates. [4] Its utilisation to make value added chemicals and larger hydrocarbons has been a challenge to industrial chemists and the catalysis community. [5] Being the smallest hydrocarbon, it is also a prototype polyatomic molecule to investigate hydrocarbon chemistry and reaction dynamics, making it a favourite amongst theoretical and physical chemists as well. [6]

Weak dispersion or van der Waals forces have been shown to define the interaction of small non-polar alkanes like methane. [7, 8] Interaction between methane molecules and the formation of dimers which are weak van der Waal's complexes have been the subject of numerous investigations. [7, 9-14] It is typically accepted that these non-covalent interactions are best understood using high level electronic structure methods that include electron 
correlation such as coupled cluster theory with up to (pertubative) triple excitations $\operatorname{CCSD}(\mathrm{T})$ together with sufficiently large basis sets, and by applying suitable corrections. [13] The potential energy curve of the methane dimer obtained using second order Møller-Plesset (MP2) perturbation theory [15] or $\operatorname{CCSD}(\mathrm{T})$ methods is characterised by a shallow well with a long range attractive tail on one side and a steeply rising head on the other. [11] The interaction energy of methane molecules in the dimer is estimated to be $1.6-2.4 \mathrm{~kJ} \mathrm{~mol}^{-1}$ with an equilibrium separation of $3.6 \AA$ to $3.7 \AA$. [10, 11] Many computational investigations aimed at obtaining an accurate description of the inter-molecular potential energy surface (PES) of the homo-dimer of methane, dimers with other small molecules $\left(\mathrm{SiH}_{4}, \mathrm{CCl}_{4}\right.$, etc.) and of small alkanes. The PES is crucial to investigate their dynamical, fluid and condensed phase properties. $[16,17]$

In spite of the vast literature on the homo-dimer of methane, characterisation of the PES of the methane dimer at inter-nuclear distances much shorter than the equilibrium separation has not been reported. Moreover, methane molecules are known to dissociate and recombine into larger hydrocarbons at extremely high pressures and temperatures, such as those existing in the interior of planets. [18-20] The mechanism of such dissociation and formation of larger hydrocarbons involving mechanical impact and collision of methane molecules may be bimolecular. The conversion of methane to ethane, ethylene, ethyne, benzene and so on in noncatalytic pyrolysis processes is believed to proceed by its unimolecular dissociation to form $\mathrm{CH}_{3}$ radicals. [21] These radicals couple to form ethane from which ethylene and other hydrocarbons may be formed. [21] Meanwhile, a bimolecular concerted mechanism for the dissociation and coupling of methane molecules has not been reported in the literature. Here, we present a concerted 'coupling-induced dissociation reaction' pathway with transition states (TSs) and energetics for the dissociation of strong $\mathrm{C}-\mathrm{H}$ bonds of methane and its direct transformation to ethane and ethylene 


\section{COMPUTATIONAL METHODS}

The geometry of the methane dimer in the $D_{3 d}$ configuration [11] was optimised using second-order Møller-Plesset (MP2) perturbation theory and the augmented correlationconsistent aug-cc-pVTZ basis set, [22] with the GAUSSIAN 09 package. [23] The potential energy of the methane dimer for C-C distances between $1.6 \AA$ and $3.7 \AA$ was also calculated by constrained geometry optimisation. A tight convergence criterion for the geometry and wavefunction was employed in all calculations. Energies were subsequently recalculated for the optimised structures using the coupled cluster with single, double, and (pertubative) triple excitations $\operatorname{CCSD}(\mathrm{T})$ method and the aug-cc-pVTZ basis set to obtain the potential energy curves shown in Fig. 1. The counterpoise correction method of Boys and Bernardi [24] was adopted to correct for basis set superposition error (BSSE). Molecular structures and vibrational modes were visualised and analysed using GaussView 05. [25] All values reported from our calculations are electronic energies unless specified otherwise.

Transition state (TS) searches were performed using UMP2/aug-cc-pVTZ and the existence of a single imaginary frequency in the vibrational frequency analysis confirmed the TS nature of the stationary point. The TSs were further connected to reactants and products by intrinsic reaction coordinate (IRC) calculations. Since UCCSD(T) is suggested to be the most accurate among the single reference computational methods, [26] energies were recalculated with UCCSD(T)/aug-cc-pVTZ. The activation enthalpies and free energies were estimated within the rigid rotor-harmonic oscillator approximation based on UMP2 geometries and harmonic frequencies at temperatures of $300 \mathrm{~K}$ and $1250 \mathrm{~K}$, with the UCCSD(T)//UMP2/augcc-pVTZ potential energies. 


\section{RESULTS AND DISCUSSION}

\subsection{Relaxed Methane Dimer Along the C-C Distance Coordinate}

The MP2 and CCSD(T)//MP2 potential energy curves of the methane dimer in the $D_{3 d}$ configuration, with the hydrogen atoms in a staggered arrangement, $[11,27]$ as a function of the C-C distance are shown in Fig.S1 of the Supplementary Information. All the C-H bonds in the molecules were fully relaxed, allowing them to stretch and bend. The same curves are shown in Fig. 1a with energy values relative to the methane dimer.

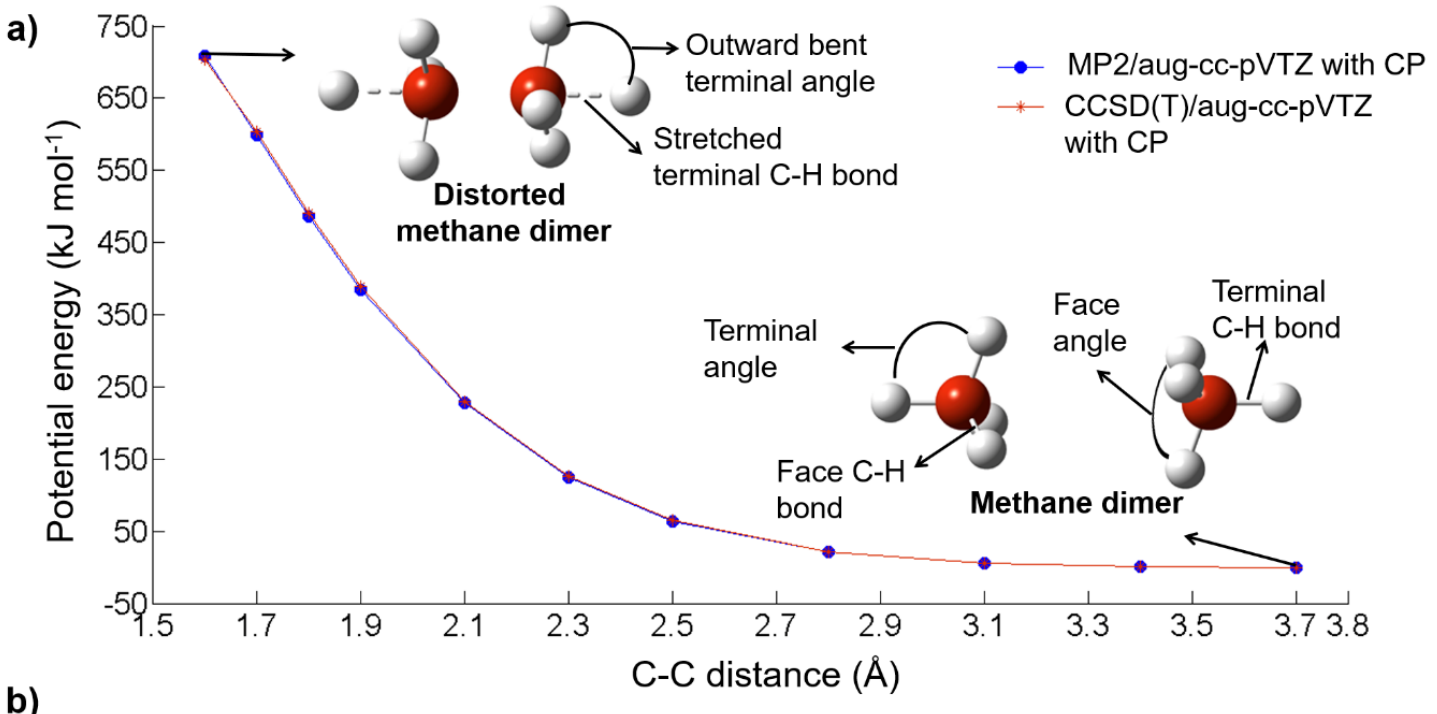

b)

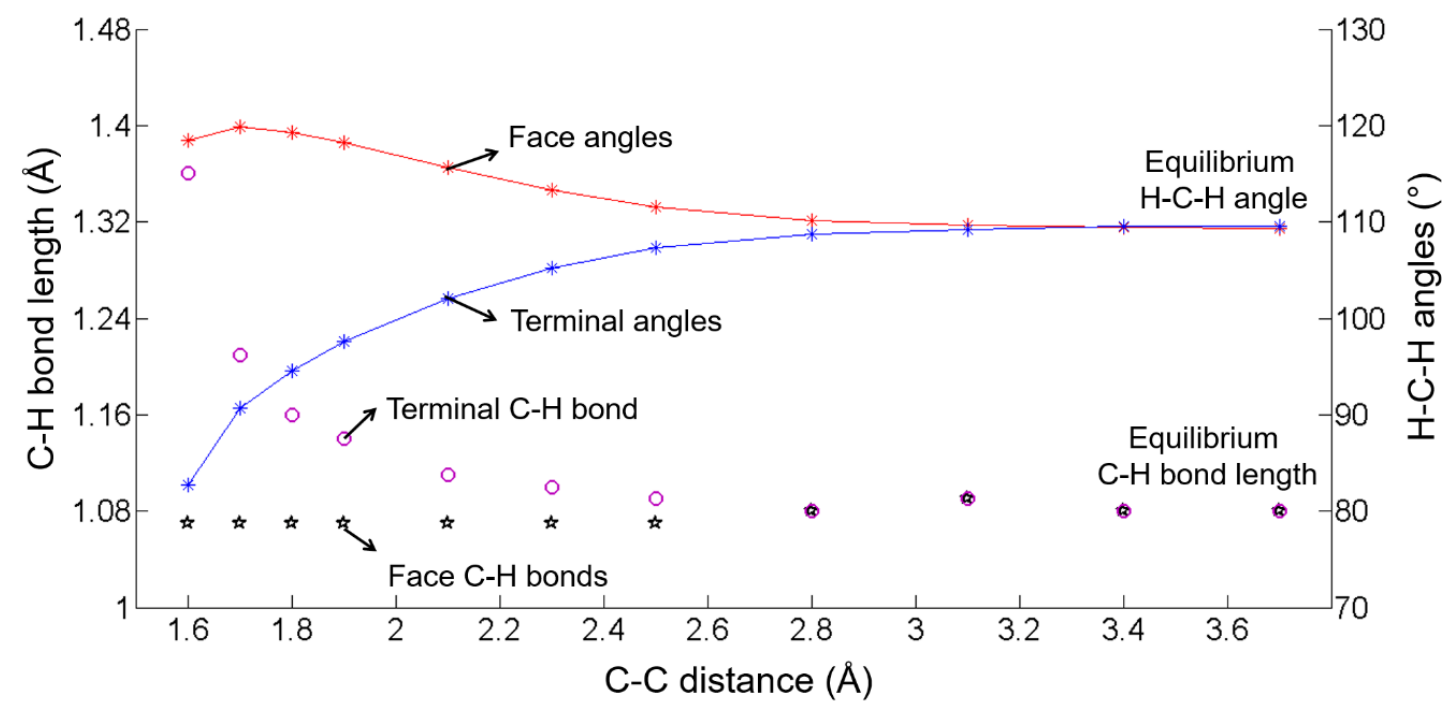

Fig. 1 a) Counterpoise corrected $\operatorname{CCSD}(\mathrm{T}) / / \mathrm{MP} 2 /$ aug-cc-pVTZ and MP2/ aug-cc-pVTZ potential energy curves of the methane dimer with all $\mathrm{C}-\mathrm{H}$ bonds relaxed. Potential energies 
are relative to that of the dimer at a C-C equilibrium distance of $3.7 \AA$. The structures corresponding to the dimer at C-C distances of $3.7 \AA$ and $1.6 \AA$ are also shown depicting the terminology used in the text for different bonds and angles. b) Variation of the terminal and face $\mathrm{C}-\mathrm{H}$ bond distances (left axis) and $\mathrm{H}-\mathrm{C}-\mathrm{H}$ angles (right axis) in the methane molecules of the dimer along the C-C distance coordinate from the MP2/aug-cc-p-VTZ optimised structures.

These curves are nearly identical with negligible difference in the calculated relative energies. This suggests that the accuracy of the MP2 method is comparable to that of the $\mathrm{CCSD}(\mathrm{T})$ method for the range of $\mathrm{C}-\mathrm{C}$ distances investigated here. However, MP2 and UMP2 methods have been shown to be inefficient compared to more advanced multi reference methods in the region of the C-H bond dissociation.[26] The potential energy rises steeply for inter-nuclear separations smaller than $2.5 \AA$. Further details regarding this PES and its characteristics are presented in section S2.1 of the Supplementary Information. Methane dimer structures along the C-C distance coordinate are characterised by significant deformation of both methane molecules from their original tetrahedral geometry. Structures corresponding to the distorted dimer at a C-C distance of $1.6 \AA$ and the equilibrium dimer at $3.7 \AA$ are presented in Fig.1a along with the definitions of the terminal and face angles and bonds.

The $\mathrm{H}-\mathrm{C}-\mathrm{H}$ angles and the $\mathrm{C}-\mathrm{H}$ bonds of the two molecules along the $\mathrm{C}-\mathrm{C}$ distance coordinate are presented in Fig. $1 \mathrm{~b}$. The terminal $\mathrm{C}-\mathrm{H}$ bonds are significantly stretched at $\mathrm{C}-\mathrm{C}$ distances shorter than $2 \AA$ while the remaining C-H bonds shrink only slightly. The face angles increase from the equilibrium value of $109.5^{\circ}$ as the $\mathrm{CH}_{3}$ fragments open up to minimise repulsions between the hydrogen atoms facing each other. As a result, the terminal angles have values lower than the equilibrium value as the face $\mathrm{C}-\mathrm{H}$ bonds rotate outwards (away from the other molecule), as shown in Fig. 1. The terminal C-H bond lengths of $1.36 \AA$ for the dimer structure at a C-C distance of $1.6 \AA$ suggest that the latter can be viewed as a precursor of 
coupling-induced dissociation of the molecules, a pathway that may open up upon high-speed collisional impact or in extreme conditions of pressure and temperature.

\subsection{Coupling-induced Dissociation of Methane Molecules to Form Ethane and Ethylene}

To investigate the coupling-induced dissociation mechanism, a transition state search was performed, starting with the distorted dimer structure at the C-C distance of $\sim 1.6 \AA$. The UMP2/aug-cc-pVTZ method was found to compare well with the UCCSD/aug-cc-pVTZ method in identifying transition state geometries and activation energy barriers. The details of the comparison are provided in section S2.2 of the Supplementary Information. Hence, for the remainder of this article, the reported geometries are obtained using the UMP2/aug-cc-pVTZ calculations, while the potential energies reported are from the UCCSD(T)/aug-cc-pVTZ calculations on the UMP2 optimised geometries.

The TSs obtained for $\mathrm{C}-\mathrm{C}$ coupling and the intrinsic reaction coordinate (IRC) tracing the descent on either side of the TS are depicted in Fig. 2. The terminal C-H bonds of both methane molecules in TS1 are stretched to $1.75 \AA$ at a C-C distance of $1.66 \AA$. The atomic motion corresponding to the imaginary-frequency mode of the TS further suggests that the dissociation of the terminal $\mathrm{C}-\mathrm{H}$ bonds of both methane molecules is concerted with the coupling of the two molecules. The products of this reaction pathway are ethane $+2 \mathrm{H}$ radicals, which may additionally serve as intermediates in the formation of ethylene and two hydrogen molecules via an additional transition state TS2, as shown in Fig. 2. The IRC along the product side of TS2 (Fig. 2) shows abstraction of one hydrogen from each $\mathrm{CH}_{3}$ fragment by each of the two eliminated terminal hydrogens and further coupling of the two carbon centres to form ethylene and two hydrogen molecules. 


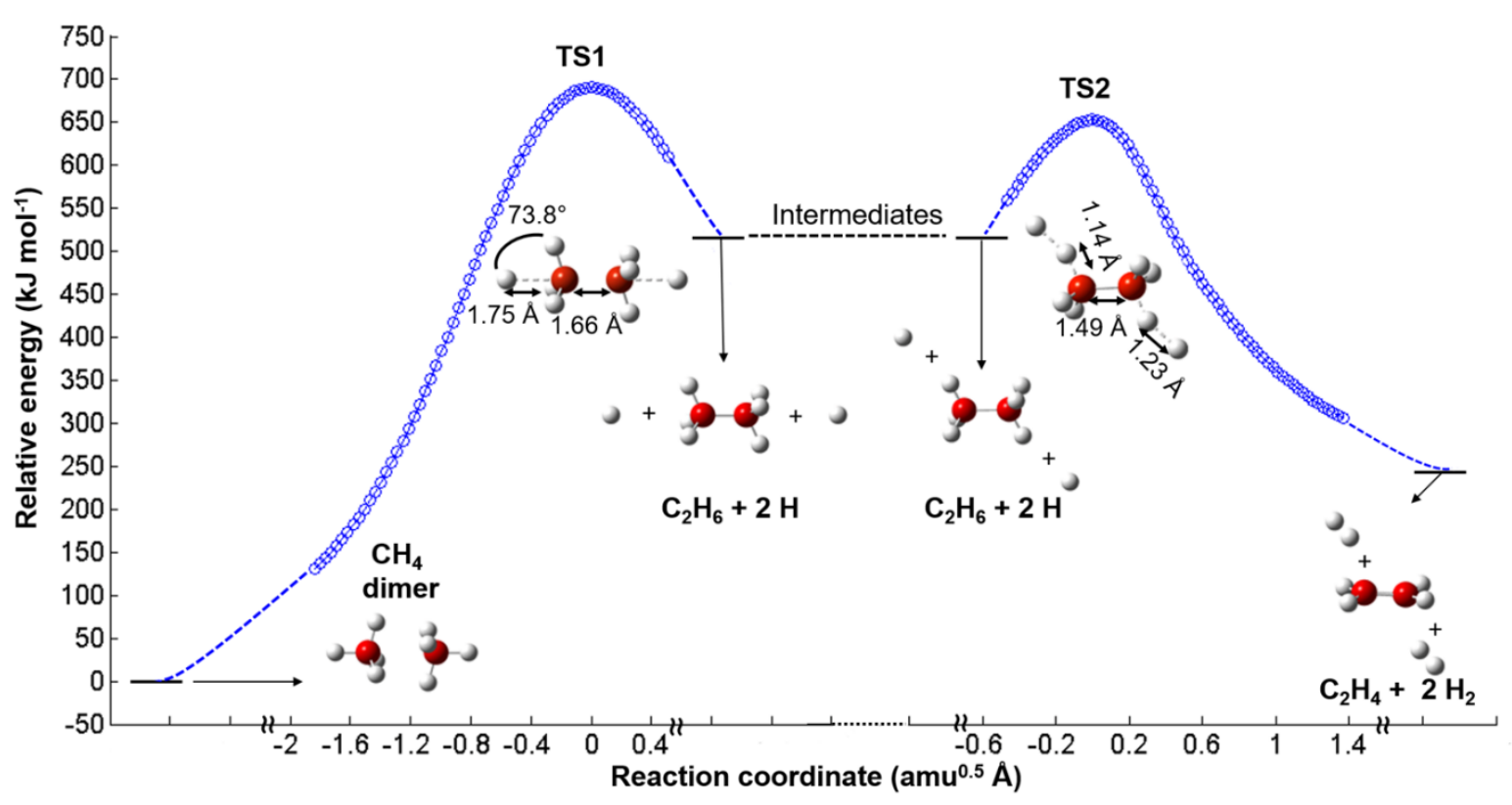

Fig. 2 Reaction profile for the coupling induced dissociation of the terminal C-H bonds of the two methane molecules, via transition state TS1, leading to formation of ethane and the subsequent dissociation to form ethylene via TS2. Points along the intrinsic reaction coordinate profile are shown as solid blue lines with circular markers and the dashed lines depict extrapolation to the optimised minima on either side of the TS. Important bond and angle parameters at the TSs are also indicated. The reported energy values are obtained using the UMP2/aug-cc-pVTZ method, relative to the methane dimer.

The UCCSD(T)//UMP2/aug-cc-pVTZ energy barrier for the bimolecular couplinginduced transformation of the methane dimer into ethane or ethylene via TS1 shown in Fig. 2 is $614.8 \mathrm{~kJ} \mathrm{~mol}^{-1}$, while the corresponding activation enthalpy barrier at $300 \mathrm{~K}\left(\Delta \mathrm{H}_{300 \mathrm{~K}}^{\ddagger}\right)$ is $579.2 \mathrm{~kJ} \mathrm{~mol}^{-1}$. The formation of ethane and two hydrogen radicals is endoergic by $532.2 \mathrm{~kJ}$ $\mathrm{mol}^{-1}\left(\Delta \mathrm{H}_{\mathrm{r}, 300 \mathrm{~K}}=493.9 \mathrm{~kJ} \mathrm{~mol}^{-1}\right)$ while the formation of ethylene and two hydrogen molecules from the intermediate, ethane $+2 \mathrm{H}$, is exoergic by $289.9 \mathrm{~kJ} \mathrm{~mol}^{-1}\left(\Delta \mathrm{H}_{\mathrm{r}, 300 \mathrm{~K}}=-292.9 \mathrm{~kJ} \mathrm{~mol}^{-1}\right)$. Although $\operatorname{UCCSD}(\mathrm{T})$ is suggested to be the ideal single reference method for calculation of activation energies of systems involving $\mathrm{C}-\mathrm{H}$ bond cleavage, [26] the $\mathrm{T} 1$ diagnostics [28] on the $\operatorname{UCCSD}(\mathrm{T})$ calculations suggest that further improvement in accuracy is possible with 
multireference computational methods. The details regarding this analysis are also presented in section S2.2 of the Supplementary Information.

In the pyrolysis of methane, the formation of ethane in the gas phase is typically expected to be the result of unimolecular dissociation of methane into methyl radicals, which subsequently couple to yield ethane. Based on the active thermochemochemical table (ATcT) thermochemical network (TN) analysis, for methane to form $\mathrm{CH}_{3}+\mathrm{H}$ at $298.15 \mathrm{~K}$, the bond dissociation enthalpy (BDE) is reported to be $438.9 \mathrm{~kJ} \mathrm{~mol}^{-1}$ and for $\mathrm{CH}_{3}$ to form $\mathrm{CH}_{2}+\mathrm{H}$ it is reported to be $463.1 \mathrm{~kJ} \mathrm{~mol}^{-1}$. [29] For gas phase radical reactions such as these, the activation energy barriers are nearly the same as the BDE. [30] In this context, the activation barrier for the direct formation of ethane by the concerted mechanism via TS1 is higher than that of the pyrolysis pathway and is a possible explanation as to why this concerted pathway may not be observed under typical pyrolysis conditions.

The particularly high energy barrier for this bimolecular coupling-induced dissociation pathway via TS1 is due to the strong repulsion between the molecules and the distortion required from their equilibrium structures along the $\mathrm{C}-\mathrm{C}$ distance coordinate. According to Bickelhaupt and co-workers, [31,32] a reaction barrier has contributions from the activation strain or the deformation of the reacting molecules and the interaction energy between the molecules along the reaction coordinate. This forms the basis of their "Activation Strain" model for chemical reactivity which gives fundamental insights into the nature and origins of the activation barriers in different reactions. [32] The energy penalty for the deformation of each methane molecule along the IRC is calculated with reference to the undistorted equilibrium methane molecule as

$$
E_{D e f}=E_{(C H 4 D)}-E_{(C H 4 E)}(1)
$$


where $E_{(C H 4 D)}$ is the energy of one of the deformed molecules in the dimer and $E_{(C H 4 E)}$ is the energy of the optimised equilibrium methane molecule. The interaction energy between the molecules is calculated as

$E_{\text {int }}=E_{(C H 4 \text { dimer })}-2 \times E_{(C H 4 D)}(2)$

where $E_{(C H 4 \text { dimer })}$ is the energy of the optimised dimer at a given C-C distance and $E_{(C H 4 D)}$ is the energy of one of the fragments in the dimer configuration. The deformation energy of each molecule and the interaction energy along the IRC are reported in Table 1. The deformation energy of each methane molecule is observed to increase rapidly from $81.3 \mathrm{~kJ}$ $\mathrm{mol}^{-1}$ at an IRC value of $-0.74 \mathrm{amu}^{0.5} \AA$ to $331.9 \mathrm{~kJ} \mathrm{~mol}^{-1}$ at the TS. The interaction energy between the two fragments on the other hand is $174.3 \mathrm{~kJ} \mathrm{~mol}^{-1}$ at the IRC value of $-0.74 \mathrm{amu}^{0.5}$ $\AA$ and decreases along the IRC, becoming negative at the TS. This reflects a transition from repulsive to attractive interactions. Thus, large deformation of the molecules and severe repulsion between the fragments are involved in this mechanism of bimolecular direct transformation of methane to ethane/ ethylene.

Table 1 Deformation Energy $\left(\mathrm{E}_{\mathrm{def}}\right)$ of One of the Methane Molecules and Interaction Energy (Eint) Between the Two Molecular Fragments Along the Intrinsic Reaction Coordinate Leading to TS1 as Shown in Fig. 2.

\begin{tabular}{|l|l|l|l|l|}
\hline \multirow{2}{*}{ IRC $\left(\mathrm{amu}^{0.5} \AA\right)$} & $\mathrm{E}_{\text {def }}\left(\mathrm{kJ} \mathrm{mol}^{-1}\right)$ & $\mathrm{E}_{\text {int }}\left(\mathrm{kJ} \mathrm{mol}^{-1}\right)$ & $\begin{array}{l}\text { Relative } \Delta \mathrm{E}_{\text {def }} \\
\left(\mathrm{kJ} \mathrm{mol}^{-1}\right)\end{array}$ & $\begin{array}{l}\text { Relative } \Delta \mathrm{E}_{\text {int }} \\
\left(\mathrm{kJ} \mathrm{mol}^{-1}\right)\end{array}$ \\
\hline-0.74 & 81.3 & 174.3 & 0.00 & 0.0 \\
\hline-0.59 & 127.2 & 178.1 & 45.88 & 3.8 \\
\hline-0.44 & 180.1 & 166.9 & 98.80 & -7.4 \\
\hline-0.30 & 233.9 & 131.5 & 152.67 & -42.8 \\
\hline
\end{tabular}




\begin{tabular}{|l|l|l|l|l|}
\hline-0.15 & 285.0 & 59.7 & 203.69 & -114.6 \\
\hline TS1 & 331.9 & -51.7 & 250.59 & -226.0 \\
\hline
\end{tabular}

Realistic high-energy collisional impact of methane molecules may involve a nonsymmetric approach and highly distorted non-equilibrium geometries, unlike those presented here. Finite temperature molecular dynamics simulations are ideal to investigate such scenarios. To investigate the validity of the proposed mechanism in the event of non-idealised collision scenarios, we simulated the collision and coupling induced dissociation of methane using ab initio molecular dynamics (AIMD) simulations with the meta-dynamics algorithm [33]. Details regarding the computational methodology adopted for these simulations and a note on the inherent deficiencies of the methodology are provided in section S1 of the Supplementary Information. The AIMD-meta-dynamics simulations of the coupling induced dissociation of two methane molecules also demonstrate the direct formation of ethane and two hydrogen radicals through a potential saddle point structure resembling TS1, which is shown in Fig.2. The highly distorted structure resembling the TS1 structure is shown in Fig.S3a of the Supplementary Information and the trajectory is provided as supplementary movie S1.

\subsection{Alternate Pathway for the Coupling-induced Dissociation of Methane Molecules to Form Ethane and Ethylene}

When the approach of the methane molecules is not head-on and symmetrical, the formation of ethane may proceed via a non-symmetric TS, in a methylene radical-like pathway with elimination of a hydrogen molecule from one of the methane molecules, as shown in Fig.3. This elimination proceeds with simultaneous transfer of hydrogen from the methane molecule to the methylene radical. The energy barrier for this coupling-induced transformation of two methane molecules into ethane and a hydrogen molecule via TS3 (shown in Fig. 3) is calculated to be $523.8 \mathrm{~kJ} \mathrm{~mol}^{-1}\left(\Delta \mathrm{H}_{300 \mathrm{~K}}^{\ddagger}=492.9 \mathrm{~kJ} \mathrm{~mol}^{-1}\right)$. AIMD-Metadynamics simulations of the 
coupling induced dissociation of two methane molecules also demonstrate the direct formation of ethane and a hydrogen molecule through a potential saddle point structure resembling TS3, which is shown in Fig.3. This structure is shown in Fig.S3 of the Supplementary Information and the trajectory is provided as supplementary movie S2.

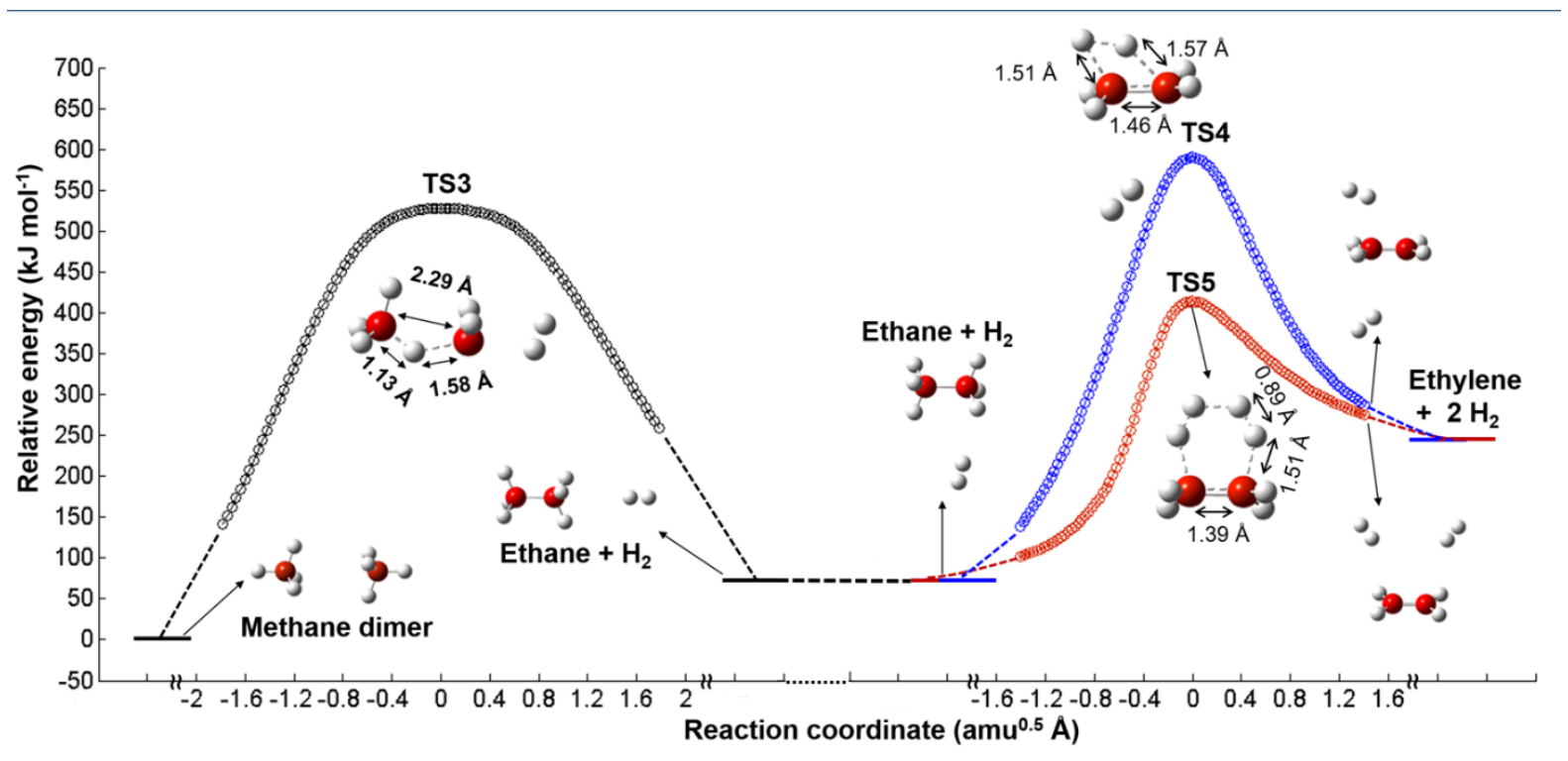

Fig. 3. Reaction profile for the formation of ethane by elimination of a hydrogen molecule from one of the methane molecules, transfer of a hydrogen atom from the other methane to the one undergoing $\mathrm{H}_{2}$ elimination and concerted coupling of the two methane molecules (left). The subsequent dehydrogenation of ethane to form ethylene in a direct un-assisted dehydrogenation mechanism via transition state TS4 and in a hydrogen assisted dehydrogenation mechanism via TS5 are shown to the right. Points along the intrinsic reaction coordinate profile are shown as solid black, blue, and red lines with circular markers and the dashed lines depict extrapolation to the optimised minima on either side of the TSs. The reported energy values are obtained using the UMP2/aug-cc-pVTZ method, relative to the equilibrium methane dimer. Important bond parameters at the TSs are indicated in the figure.

Ethane formed in the above pathway can undergo further dehydrogenation to form ethylene and an additional hydrogen molecule via two different pathways. When dehydrogenation of ethane proceeds with no assistance from the first eliminated hydrogen 
molecule, the additional hydrogen molecule is generated via TS4, as shown in Fig. 3. The energy barrier for the dehydrogenation in this pathway is $511.3 \mathrm{~kJ} \mathrm{~mol}^{-1}\left(\Delta \mathrm{H}^{\ddagger} 300 \mathrm{~K}=484.8 \mathrm{~kJ}\right.$ $\mathrm{mol}^{-1}$ ). Since elimination of two hydrogens from the same $\mathrm{CH}_{3}$ moiety of ethane is energetically unfavourable, dehydrogenation proceeds via elimination of one hydrogen atom from each $\mathrm{CH}_{3}$ moiety of ethane. ATcT TN analysis gives the bond dissociation enthalpy for the first $\mathrm{C}-\mathrm{H}$ bond of ethane, i.e. the barrier for formation of $\mathrm{CH}_{3} \mathrm{CH}_{2}$, as $421.7 \mathrm{~kJ} \mathrm{~mol}^{-1}$ at $298.15 \mathrm{~K}$. [29] Subsequent $\mathrm{C}-\mathrm{H}$ bond activation has a barrier of $452.61 \mathrm{~kJ} \mathrm{~mol}^{-1}$ for the formation of $\mathrm{CH}_{3} \mathrm{CH}$, while the barrier for the formation of $\mathrm{CH}_{2} \mathrm{CH}_{2}$ is much lower at $150.59 \mathrm{~kJ} \mathrm{~mol}^{-1}$. [29] Thus, the additional hydrogen molecule generated along the pathway via TS4 has its hydrogen atoms originating from each $\mathrm{CH}_{3}$ moiety of ethane.

Ethane formed from methane dimer dehydrogenation may also undergo dehydrogenation assisted by the first eliminated hydrogen molecule via TS5 as shown in Fig.3. Each hydrogen atom of the previously eliminated hydrogen molecule abstracts one hydrogen each from the two $\mathrm{CH}_{3}$ moieties of ethane to form two hydrogen molecules. The energy barrier for dehydrogenation via this pathway is significantly lower, at $345.1 \mathrm{~kJ} \mathrm{~mol}^{-1}\left(\Delta \mathrm{H}^{\ddagger} 300 \mathrm{~K}=322.6\right.$ $\left.\mathrm{kJ} \mathrm{mol}^{-1}\right)$, than the energy barrier for the unassisted dehydrogenation at $511.3 \mathrm{~kJ}$ mol-1 $\left(\Delta \mathrm{H}^{\ddagger} 300 \mathrm{~K}\right.$ $\left.=484.8 \mathrm{~kJ} \mathrm{~mol}^{-1}\right)$. The presence of hydrogen is known to have a favourable impact during pyrolysis of methane as the decomposition of methane in the presence of molecular hydrogen starts at temperatures around $700-800^{\circ} \mathrm{C}$ while pure methane does not decompose at temperatures lower than $1000{ }^{\circ} \mathrm{C} .[34]$

All pathways characterised for the formation of ethane and ethylene from two methane molecules and their energy barriers are summarised in Fig. 4. The two different sets of reaction paths discussed earlier are 1) bimolecular coupling- induced direct dissociation of the two molecules via TS1 and TS2 to form ethane and ethylene, respectively; 2) bimolecular couplinginduced dissociation via TS3 to form ethane and its dehydrogenation to form ethylene. Figure 
4 shows that the formation of ethane and $\mathrm{H}_{2}$ is energetically more favourable compared to ethylene and two $\mathrm{H}_{2}$ molecules.

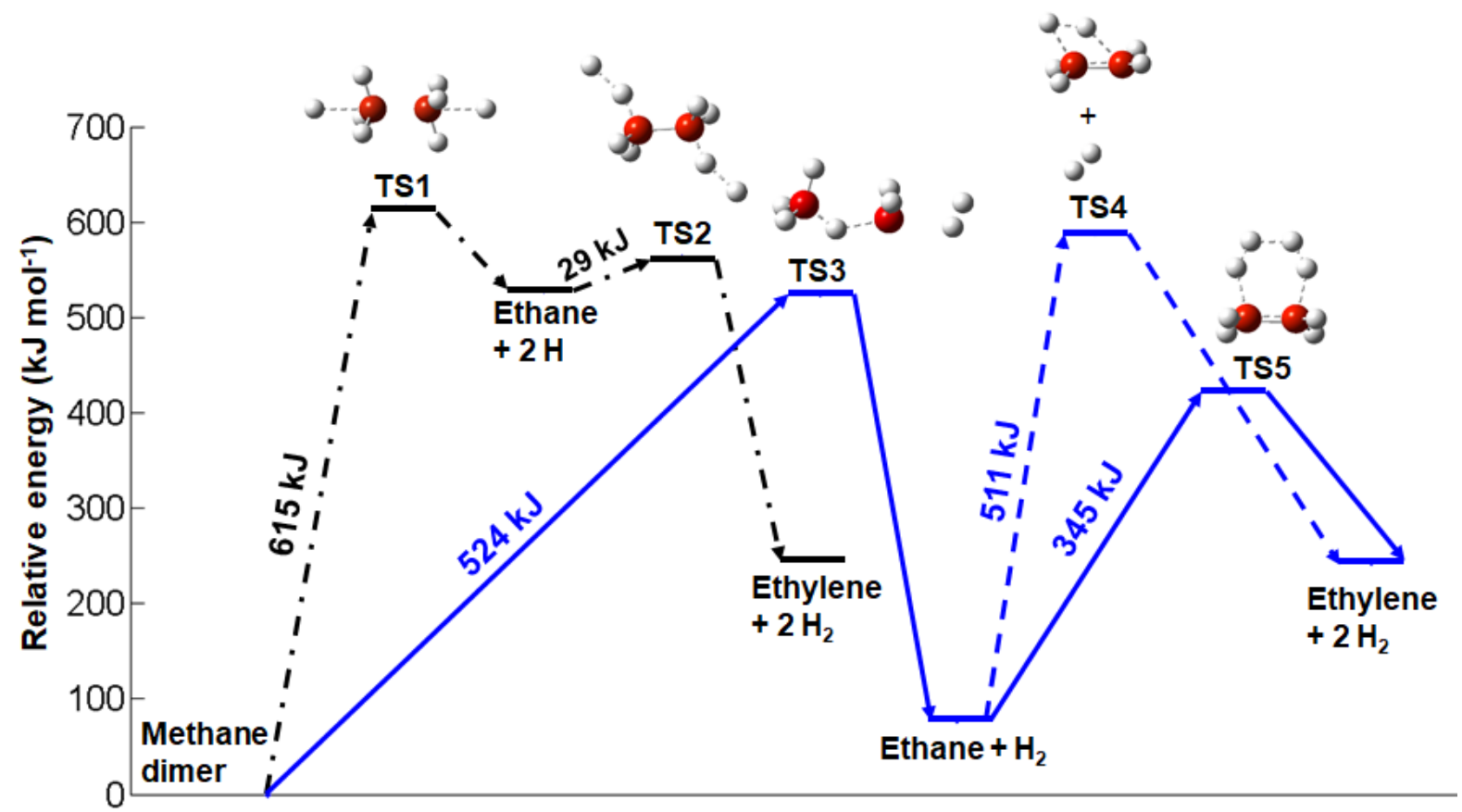

Fig. 4. Pathways characterised for the transformation of two methane molecules to ethane and ethylene. The transition states (TSs) for each pathway and the energy barriers relative to the equilibrium methane dimer obtained using the UCCSD(T)//UMP2/aug-cc-pVTZ combination is shown.

The energetics of the different reaction pathways shown in Fig. 4 are collected in Table 2, along with the activation free energy barrier and free energy change for each pathway at temperatures of $300 \mathrm{~K}$ and $1250 \mathrm{~K}$ to shed light on the thermodynamics and kinetics of the processes. The activation free energy barrier for the direct bimolecular coupling-induced dissociation of methane and formation of ethane and ethylene is observed to increase by over $100 \mathrm{~kJ} \mathrm{~mol}^{-1}$ when the temperature increases from $300 \mathrm{~K}$ to $1250 \mathrm{~K}$. But the formation of ethylene becomes thermodynamically more favourable at $1250 \mathrm{~K}$ compared to $300 \mathrm{~K}$, although the change in free energy is still positive. The activation free energy barrier for the formation of ethane and $\mathrm{H}_{2}$ via TS3 is much lower than that for the formation of ethylene and $2 \mathrm{H}_{2}$ via 
TS1 and TS2, irrespective of the temperature. Additionally, formation of ethane is thermodynamically more favourable than formation of ethylene. The thermodynamic trends for the transformation of methane to ethane and ethylene are in agreement with those reported in the literature. [34,35] Similarly, the transformation of ethane to ethylene, although not spontaneous, is more favourable at higher temperatures. From Table 2, it can be deduced that stepwise transformation of methane via ethane is the most favourable pathway for formation of ethylene from methane.

Table 2 Energetics of Transformation of Two Methane Molecules to Ethane and Ethylene via Different Reaction Pathways.

\begin{tabular}{|c|c|c|c|c|c|c|}
\hline Reaction pathway & $\mathrm{E}^{\ddagger}(\mathrm{kJ}$ & $\Delta \mathrm{E}(\mathrm{kJ}$ & $\Delta \mathrm{G}_{300 \mathrm{~K}}^{\ddagger}$ & $\Delta \mathrm{G}_{300 \mathrm{~K}}(\mathrm{~kJ}$ & $\Delta \mathrm{G}_{1250 \mathrm{~K}}^{\ddagger}$ & $\Delta \mathrm{G}_{1250 \mathrm{~K}}$ \\
& $\left.\mathrm{~mol}^{-1}\right)$ & $\left.\mathrm{mol}^{-1}\right)$ & $\left(\mathrm{kJ} \mathrm{mol}^{-1}\right)$ & $\left.\mathrm{mol}^{-1}\right)$ & $\left(\mathrm{kJ} \mathrm{mol}^{-1}\right)$ & $\left(\mathrm{kJ} \mathrm{mol}^{-1}\right)$ \\
\hline Via TS1 $\left(2 \mathrm{CH}_{4} \rightarrow\right.$ & 614.8 & 532.2 & 612.6 & 486.5 & 717.1 & 448.7 \\
$\left.\mathrm{C}_{2} \mathrm{H}_{6}+2 \mathrm{H}\right)$ & & & & & & \\
\hline Via TS1, TS2 $\left(2 \mathrm{CH}_{4}\right.$ & 614.8 & 242.6 & 612.6 & 189.1 & 717.1 & 113.9 \\
\hline $\left.\mathrm{C}_{2} \mathrm{H}_{4}+2 \mathrm{H}_{2}\right)$ & & & & & & \\
\hline Via TS3 $\left(2 \mathrm{CH}_{4} \rightarrow\right.$ & 523.9 & 77.9 & 511.3 & 73.8 & 560.4 & 97.1 \\
$\left.\mathrm{C}_{2} \mathrm{H}_{6}+\mathrm{H}_{2}\right)$ & & & & & & \\
\hline Via TS4 $\left(\mathrm{C}_{2} \mathrm{H}_{6}+\mathrm{H}_{2} \rightarrow\right.$ & 511.3 & 165.1 & 492.2 & 113.8 & 513.4 & 9.9 \\
$\left.\mathrm{C}_{2} \mathrm{H}_{4}+2 \mathrm{H}_{2}\right)$ & & & & & & \\
\hline Via TS5 $\left(\mathrm{C}_{2} \mathrm{H}_{6}+\mathrm{H}_{2} \rightarrow\right.$ & 345.1 & 165.1 & 345.8 & 113.6 & 431.7 & 9.3 \\
$\left.\mathrm{C}_{2} \mathrm{H}_{4}+2 \mathrm{H}_{2}\right)$ & & & & & & \\
\hline
\end{tabular}

\section{CONCLUSIONS}


Compression of the methane dimer, bringing methane molecules closer together than the equilibrium dimer separation of $\sim 3.7 \AA$, may result in bimolecular coupling-induced dissociation of the two methane molecules and their transformation to ethane or ethylene. One of the pathways implicates coupling-induced dissociation of the terminal $\mathrm{C}-\mathrm{H}$ bonds of both methane molecules and results in the formation of ethane and two hydrogen radicals. Further transformation to ethylene and two hydrogen molecules involves abstraction of hydrogen atoms from each $\mathrm{CH}_{3}$ moiety by the hydrogen radicals. The energy barrier for this transformation mechanism is relatively high due to the strong repulsion between the molecules along the line of approach.

The coupling-induced transformation of two methane molecules to form ethane may also proceed via molecular hydrogen elimination from one of the methane molecules accompanied by intermolecular transfer of a hydrogen atom. The energy barrier along this pathway is lower than that for the pathway involving the elimination of terminal hydrogen atoms of both molecules. Ethane may be further dehydrogenated to form ethylene via two pathways: 1) without assistance from the initially released hydrogen molecule, where the additional hydrogen molecule is formed from one hydrogen atom coming from each $\mathrm{CH}_{3}$ fragment of ethane, and 2) with assistance from the eliminated hydrogen molecule, where the initially released hydrogen molecule splits and abstracts one hydrogen atom from each $\mathrm{CH}_{3}$ fragment. The hydrogen-assisted dehydrogenation of ethane has an activation barrier much lower than that for the non-assisted pathway. The formation of ethylene and two hydrogen molecules is not spontaneous, but becomes more favourable at high temperatures above $1250 \mathrm{~K}$.

The mechanisms reported here may be those implicated in the conversion of methane to larger hydrocarbons in the interior of planets, including earth. At high temperatures and pressures, mechanical impact of the molecules may cause their compression and coupling, as discussed above. Further ab initio molecular dynamics simulations and molecular beam 
experiments may shed more light on the product distribution and controlling factors in high speed collision of methane molecules.

\section{SUPPLEMENTARY MATERIAL}

Supplementary information file contains details regarding computational methods used in the $a b$ initio molecular dynamics and meta-dynamics investigation of the coupling induced dissociation of methane molecules along with the suitability of such methods, discussion on the dimer energy profile and the effect of basis set superposition errors, rationale for the use of $\mathrm{UCCSD}(\mathrm{T}) / / \mathrm{UMP} 2 /$ aug-cc-pVTZ method for calculating activation barriers and reaction energies, discussion on the direct transformation of the methane dimer to ethane/ethylene, and cartesian coordinates of all stationary point structures. Additional supplementary movies representing the coupling induced dissociation of methane and formation of ethane in two different pathways as obtained from the ab initio molecular dynamics and meta-dynamics simulations are included as movies S1 and S2.

\section{ACKNOWLEDGEMENT}

JJV, BS and SHM would like to acknowledge financial support provided by Nanyang Technological University, Singapore. GHP and HV are grateful to the Programme International de Coopération Scientifique (PICS) of the French Centre National de la Recherche Scientifique (CNRS) for supporting the early stages of the collaboration that led to this work. HV acknowledges the continuous support of IDRIS (Grant i2016-090642). GHP acknowledges partial support of the Natural Science and Engineering Research Council (NSERC) of Canada for this work.

\section{REFERENCES}

[1] Hubbard, W. B., Interiors of the Giant Planets. Science 1981, 214, 145-149. 
[2] El-Kader, M. S. A.; Maroulis, G., New Insights into Collision-Induced Rototranslational Absorption and Scattering Spectra of Gaseous Methane at Different Temperatures. J. Mol. Spectrosc. 2012, 281, 28-39.

[3] BP Statistical Review of World Energy June 2017, British Petroleum, (www.bp.com/statisticalreview), 2017.

[4] Dawe, R. A.; Thomas, S., A Large Potential Methane Source - Natural Gas Hydrates. Energy Sources, Part A 2007, 29, 217-229.

[5] Lunsford, J. H., Catalytic Conversion of Methane to More Useful Chemicals and Fuels: A Challenge for the $21^{\text {st }}$ Century. Catal. Today 2000, 63, 165-174.

[6] Juurlink, L. B. F.; Killelea, D. R.; Utz, A. L., State-Resolved Probes of Methane Dissociation Dynamics. Prog. Surf. Sci. 2009, 84, 69-134.

[7] Szczęśniak, M. M.; Chałasiński, G.; Cybulski, S. M.; Scheiner, S., Intermolecular Potential of the Methane Dimer and Trimer. J. Chem. Phys. 1990, 93, 4243-4253.

[8] Echeverría, J.; Aullón, G.; Danovich, D.; Shaik, S.; Alvarez, S., Dihydrogen Contacts in Alkanes Are Subtle but Not Faint. Nat. Chem. 2011, 3, 323-330.

[9] Chen, X. R.; Bai, Y. L.; Zhu, J.; Yang, X. D., Intermolecular Interaction Potentials of the Methane Dimer from the Local Density Approximation. Phys. Rev. A: At., Mol., Opt. Phys. 2004, 69, 034701.

[10] Li, A. H. T.; Chao, S. D., Intermolecular Potentials of the Methane Dimer Calculated with Møller-Plesset Perturbation Theory and Density Functional Theory. J. Chem. Phys. 2006, 125, 094312.

[11] Li, A. H. T.; Chao, S. D., Interaction Energies of Dispersion-Bound Methane Dimer from Coupled Cluster Method at Complete Basis Set Limit. J. Mol. Struct.: THEOCHEM 2009, 897, 90-94. 
[12] Chao, S. D.; Li, A. H. T., Comparative Performance of Exchange and Correlation Density Functionals in Determining Intermolecular Interaction Potentials of the Methane Dimer. $J$. Phys. Chem. A 2007, 111, 9586-9590.

[13] David Sherrill, C.; Takatani, T.; Hohenstein, E. G., An Assessment of Theoretical Methods for Nonbonded Interactions: Comparison to Complete Basis Set Limit Coupled-Cluster Potential Energy Curves for the Benzene Dimer, the Methane Dimer, Benzene-Methane, and Benzene-H ${ }_{2}$ S. J. Phys. Chem. A 2009, 113, 10146-10159.

[14] Biller, M. J.; Mecozzi, S., A High Level Computational Study of the $\mathrm{CH}_{4} / \mathrm{CF}_{4}$ Dimer: How Does It Compare with the $\mathrm{CH}_{4} / \mathrm{CH}_{4}$ and $\mathrm{CF}_{4} / \mathrm{CF}_{4}$ Dimers? Mol. Phys. 2012, 110, 377 387.

[15] Møller, C.; Plesset, M. S., Note on an Approximation Treatment for Many-Electron Systems. Phys. Rev. 1934, 46, 618-622.

[16] Jalkanen, J. P.; Pakkanen, T. A.; Yang, Y.; Rowley, R. L., Interaction Energy Surfaces of Small Hydrocarbon Molecules. J. Chem. Phys. 2003, 118, 5474-5483.

[17] Chattoraj, J.; Risthaus, T.; Rubner, O.; Heuer, A.; Grimme, S., A Multi-Scale Approach to Characterize Pure $\mathrm{CH}_{4}, \mathrm{CF}_{4}$, and $\mathrm{CH}_{4} / \mathrm{CF}_{4}$ Mixtures. J. Chem. Phys. 2015, 142, 164508.

[18] Benedetti, L. R.; Nguyen, J. H.; Caldwell, W. A.; Liu, H.; Kruger, M.; Jeanloz, R., Dissociation of $\mathrm{CH}_{4}$ at High Pressures and Temperatures: Diamond Formation in Giant Planet Interiors? Science 1999, 286, 100-102.

[19] Kolesnikov, A.; Kutcherov, V. G.; Goncharov, A. F., Methane-Derived Hydrocarbons Produced under Upper-Mantle Conditions. Nat. Geosci. 2009, 2, 566-570.

[20] Spanua, L.; Donadio, D.; Hohl, D.; Schwegler, E.; Galli, G., Stability of Hydrocarbons at Deep Earth Pressures and Temperatures. Proc. Nat. Acad. Sci. USA 2011, 108, 6843-6846. [21] Holmen, A.; Olsvik, O.; Rokstad, O. A., Pyrolysis of Natural Gas: Chemistry and Process Concepts. Fuel Process. Technol. 1995, 42, 249-267. 
[22] Dunning Jr, T. H., Gaussian Basis Sets for Use in Correlated Molecular Calculations. I. The Atoms Boron through Neon and Hydrogen. J. Chem. Phys. 1989, 90, 1007-1023.

[23] Gaussian 09, Revision D.01, Frisch, M. J.; Trucks, G. W.; Schlegel, H. B.; Scuseria, G. E.; Robb, M. A.; Cheeseman, J. R.; Scalmani, G.; Barone, V.; Mennucci, B.; Petersson, G. A.; et al., Gaussian, Inc., Wallingford CT, 2009.

[24] Boys, S. F.; Bernardi, F., The Calculation of Small Molecular Interactions by the Differences of Separate Total Energies. Some Procedures with Reduced Errors. Mol. Phys. 1970, 19, 553-566.

[25] GaussView 05, v.5.0.9, Dennington;, R.; Keith;, T.; Millam, J., Semichem Inc., Shawnee Mission, KS, 2009.

[26] Sherrill, C. D.; Dutta, A.; Abrams, M. L.; Sears, J. S., Bond Breaking in Quantum Chemistry: A Comparison of Single- and Multi-Reference Methods. In Electron Correlation Methodology, American Chemical Society: 2007; Vol. 958, pp 75-88.

[27] Hellmann, R.; Bich, E.; Vogel, E., Ab Initio Intermolecular Potential Energy Surface and Second Pressure Virial Coefficients of Methane. J. Chem. Phys. 2008, 128, 214303.

[28] Lee, T. J.; Taylor, P. R., A Diagnostic for Determining the Quality of Single-Reference Electron Correlation Methods. Int. J. Quantum Chem. 1989, 36, 199-207

[29] Ruscic, B., Active Thermochemical Tables: Sequential Bond Dissociation Enthalpies of Methane, Ethane, and Methanol and the Related Thermochemistry. J. Phys. Chem. A 2015, $119,7810-7837$.

[30] Kondrat'Ev, V. N., Chapter 5 - Unimolecular and Termolecular Reactions in Chemical Kinetics of Gas Reactions, Pergamon: 1964; pp 283-345.

[31] Van Zeist, W. J.; Bickelhaupt, F. M., The Activation Strain Model of Chemical Reactivity. Org. Biomol. Chem. 2010, 8, 3118-3127. 
[32] Fernández, I.; Bickelhaupt, F. M., The Activation Strain Model and Molecular Orbital Theory: Understanding and Designing Chemical Reactions. Chem. Soc. Rev. 2014, 43, 49534967.

[33] Laio, A.; Parrinello, M., Escaping Free-Energy Minima. Proc. Nat. Acad. Sci. USA 2002, $99,12562-12566$.

[34] Guéret, C.; Daroux, M.; Billaud, F., Methane Pyrolysis: Thermodynamics. Chem. Engg. Sci. 1997, 52, 815-827.

[35] Crabtree, R. H., Aspects of Methane Chemistry. Chem. Rev. 1995, 95, 987-1007. 